\title{
The transcriptional regulator gene E2 of the Human Papillomavirus (HPV) 16 influences the radiosensitivity of cervical keratinocytes
}

\author{
Katja Lindel ${ }^{* *}$, Stefan Rieken ${ }^{1}$, Sigrid Daffinger ${ }^{1}$, Klaus J Weber ${ }^{1}$, Ethel-Michele de Villiers ${ }^{2}$ and Jürgen Debus ${ }^{1}$
}

\begin{abstract}
Background: Clinical studies have demonstrated that HPV induced tumors constitute a specific subclass of cancer with a better response to radiation treatment. The purpose of this study was to investigate meaning of viral E2-gene for radiosensitivity.

Methods: W12 cells contain episomal HPV 16 genomes, whereas S12 cells, which derive from the W12 line, contain HPV DNA as integrated copies. Clonogenic survival was analyzed using 96-well in vitro test. Using flow cytometry cell cycle analyses were performed. Expression of $p R b$ and $p 53$ were analyzed using intracellular staining.

Results: W12 cells (intact E2 gene) showed a lower survival fraction than $\mathrm{S} 12$ cells. W12 cells developed a G2/M block $24 \mathrm{~h}$ after irradiation with 2 Gy whereas S12 showed no G2/M bloc. After irradiation S12 cells developed polyploidy and pRb-positive cells decreased. W12 cells showed no change of pRb-positive cells.

Conclusions: Depending on E2 gene status differences in cell cycle regulation might cause radioresistance. The E2/E7/pRb pathway seems to influence HPV-induced radiosensitivity. Our experiments demonstrated an effect of HPV on radiosensitivity of cervical keratinocytes via viral transcription regulator E2 pathway.
\end{abstract}

Keywords: Human Papillomavirus, Radiosensitvity, E2-gene, Cervical keratinocytes

\section{Background}

Cervical cancer is considered to be a sexually transmitted disease and has been correlated with Human Papillomavirus infection (HPV) [1]. Besides a number of prognostic factors like depth of stromal invasion, tumor differentiation or nodal involvement, presence of Human Papillomavirus has been suggested an important marker of disease severity in cervical cancer [2]. The viral genome is organized into three general segments of unequal size: long control region (LCR), early (E) and late (L) genes. Acting as transcriptional activator or repressor, E2 protein regulates virus transcription and genome replication [3]. Loss of E2 gene integrity seems to play a role for outcome and local control in cervical carcinomas $[4,5]$. It controls transcription of oncogenes E6 and E7 which

\footnotetext{
* Correspondence: katja.lindel@med.uni-heidelberg.de

'Dept. of Radiation Oncology and Radiotherapy, University of Heidelberg, Im Neuenheimer Feld 400, Heidelberg 69120, Germany

Full list of author information is available at the end of the article
}

manipulate cell cycle and ability of apoptosis [6]. There may be a possible correlation between radiotherapy, E2 function and outcome $[4,7,8]$. The E6 oncoprotein can form a complex with host cell p53 tumor suppressor protein and inducing p53 degradation and overcoming $\mathrm{G}_{1} / \mathrm{S}$ checkpoint control in DNA-damaged cells [9]. E7 oncoprotein binds to hypophosphorylated $p R b$ form resulting in its degradation and inappropriate release of E2F transcription factor [10]. Pre-clinical data arising from comparison between non-HPV-tumor cells and their counterparts transfected with sequences of HPV genome should be interpreted with caution because artificial induced expression might not mirror in vivo reality. To avoid artificial uncertainties we used W12/S12 cell model derived from a low grade cervical lesion by Stanley MA et al. 1989[11] to evaluate the influence of E2 on intrinsic radiosensitivity of cervical cells to support the hypothesis of E2-gene status as a predictive marker for therapeutic outcome in cervical cancer patients. 


\section{Methods}

\section{Cell lines and cell culture}

W12 cell line was derived from a low grade cervical lesion by Stanley MA et al. 1989, and is unique among HPV16-containing cell lines in carrying its HPV 16 genome as a multicopy episome [11]. We made use of a pair of isogenic cell lines, W12 and S12 to compare difference of survival after irradiation. W12 cells contain episomal HPV 16 genomes, whereas S12 cells, which derived from the W12 line, contain HPV DNA as integrated copies [12].

W12 cells were cultured with lethally irradiated Swiss 3T3 feeder cells and in medium consisting a mix of onequarter Dulbecco's modified eagle's medium (Gibco) and three-quarters Ham F-12 medium (Gibco) containing 5\% fetal calf serum, penicillin, streptomycin, an supplements (all from Sigma) as follows: 8.4.ng of cholera toxin $/ \mathrm{ml}$, $5 \mu \mathrm{g}$ of insulin/ml, $24.3 \mu \mathrm{g}$ of adenine/ml, $0.5 \mu \mathrm{g}$ of hydrocortisone $/ \mathrm{ml}$ and $10 \mathrm{ng}$ of epithelial growth factor per $\mathrm{ml}$. Cells were split when reached $80 \%$ confluence. S12 cells were obtained by collecting surviving W12 cells cultured without feeder layer support.

\section{E2-gene specific PCR}

HPV16-positive cells were tested for an intact E2 gene in three separate amplification reactions which allows amplifying three amplicons of different length determining integrity of E2-gene [8]. The procedure and primer sequences used were as described in the same reference.

\section{Clonogenic growth assay and irradiation}

Clonogenic survival was analyzed by using 96-well in vitro test as followed: 1-100 cells per well were seed. The plates were examined with an inverted phase contrast microscope at intervals of 7, 10, 14 days. A well was considered positive when a colony in it reached a size of 50 cells or more. Cells were fixed with $70 \%$ for ten minutes prior staining with $0.1 \%$ methylene-blue. After staining weels were washed with destilled water. Plating efficiency (PE) was calculated using poisson statistics according to formula $\mathrm{PE}=-\ln$ (neg wells/total wells)/ number of cells plated per well [13]. In radiation experiments fraction of survival was determined by dividing number of positive wells/plate/number of cells plated per well in irradiation group by number of positive wells/plate/number of cells plated per well in control plates. At least three plates were used for each group.

Cells were irradiated with singles doses of $0 \mathrm{~Gy}, 1 \mathrm{~Gy}$, 2 Gy, 3 Gy, 4 Gy, 5 Gy and 7 Gy. In such experiments, an increasing number of cells plated for each increment in radiation dose. Therefore, effect of cell number per well on plating efficiency was evaluated. Plating densities of 1-10 cell/weel were tested. Although number of wells with colonies increased with higher cell density, plating efficiency was not effected by number of cells. When 10 cells/well were used all wells in this set of experiments contained colonies.

Survival curves were based on number of positive wells or colonies in each irradiated group as a fraction of that in control group. Survival curves where calculated using Sigma Plot 8.0. At least three experiments where performed for each dose point.

\section{Cell cycle analyses}

Cell cycle analyses were performed after $0 \mathrm{~h}, 6 \mathrm{~h}, 12 \mathrm{~h}$, $24 \mathrm{~h}, 48 \mathrm{~h}$ and 7 days irradiation with 2 Gy and 7 Gy using flow cytometry using Propidium-Iodid (PI)-staining as described elsewhere [14]. Data were collected by using FACScan flow cytometry, and results were analyzed by using cellquest software (both from Becton Dickenson). For each sample, 10000 events were collected, and aggregated cells were gated out.

\section{Intracellular cytokine staining: pRb and p53}

The retinoblastoma gene encodes a nuclear phosphoprotein which is expressed in most normal cells and acts as a tumor suppressor. An underphophorylated form of Rb binds to viral oncogene HPV-E7[3]. Clone G3-245 recognizes an epitope between amino acids 300-380 of the human retinoblastoma protein (pp110-114 Rb).

Wildtype p53 formes specific complexes with several viral oncogenes including HPV-E6 and plays a role as checkpoint protein for DNA damage during $\mathrm{G} 1 / \mathrm{S}$-phase of cell cycle[9]. Clone G59-12 recognize mutant and wild type human, mouse and rat p53 suppressor protein.

The G3-245 or G59-12 and MOPC-21 FITC (a mouse IgG1 isotype control) conjugates are matched and F/P ratios determined experimentally by flow cytometric analysis.

Details of the procedure are described as follows:

Ethanol fixated cells were washed two times in cold PBS then resuspended in Fixation/Permialisation solution Perm/Wash ${ }^{\mathrm{TM}} \mathrm{BD}\left(1 \times 10^{6} \mathrm{cell} / \mathrm{ml}\right)$ for $30 \mathrm{~min}$ at $4^{\circ} \mathrm{C}$ and pelleted by centrifugation. Afterwards buffer was removed and cells were washed two times in fresh Perm/ Wash $^{\mathrm{TM}}$ BD buffer. Thoroughly resuspended cells were subjected to intracellular cytokine staining by incubating in $100 \mu \mathrm{l} \mathrm{Perm} / \mathrm{Wash}^{\mathrm{TM}}$ BD buffer containing $20 \mu \mathrm{l}$ of Fluorochrome-conjugated antibody Rb-ak (FITC Mouse AntiHuman Retinoblastoma Anti-Body from Becton Dickinson, BD-Set:\# 556538 Clone G3-245) for $24 \mathrm{~h}$ at $4^{\circ} \mathrm{C}$ temperature in the dark. After washing with Perm/Wash ${ }^{\mathrm{TM}} \mathrm{BD}$ cells were pelleted and resuspended cells in 0,5 ml Perm/ Wash $^{\mathrm{TM}} \mathrm{BD}$ for flow cytometric analysis. The same procedure was performed for p53 staining using $20 \mu \mathrm{l}$ of Fluorochrome-conjugated antibody p53-ak (FITC Mouse Anti-Human p53 Anti-Body from Becton Dickinson, Clone G59-12). 


\section{Flow cytometric analysis}

Stained cells were analyzed using FACSCan flow cytometry (BD) equipped with a air-cooled $488 \mathrm{~nm}$ argon-ion laser. Data acquisition and analysis were performed using FACSComp and CELLQuest (version 3.4) software. A total event of 10000 cells were acquired for each sample. Data were expressed as geometric mean fluorescence intensity and as ratio between fluorescence emission of sample cells and that of isotypic control ( $\mathrm{P} / \mathrm{N}$ ratio; positive/ negative). In each case negative control were cells treated as described above without Rb-ak staining or p53-ak staining. Isotypic control were cells treated with isotype-matched control of irrelevant specificity from FITC Mouse IgG1 Isotype control (BD-Set\# 556538) instead of Rb-ak staining or p53-ak staining. Analyses were performed after $0 \mathrm{~h}$ and $24 \mathrm{~h}$ irradiation with $2 \mathrm{~Gy}$ and $7 \mathrm{~Gy}$.

\section{Results}

Intact E2-gene leads to higher radiation sensitivity in cervical cells

The E2 gene of S12 cells (passage 88 - 103) was disrupted in the E2C region. W12 cells (passage 8 -14) with an intact E2 gene showed a higher radiosensitivity with a radiation enhancement factor of 1.5 (4 Gy) (Figure 1).

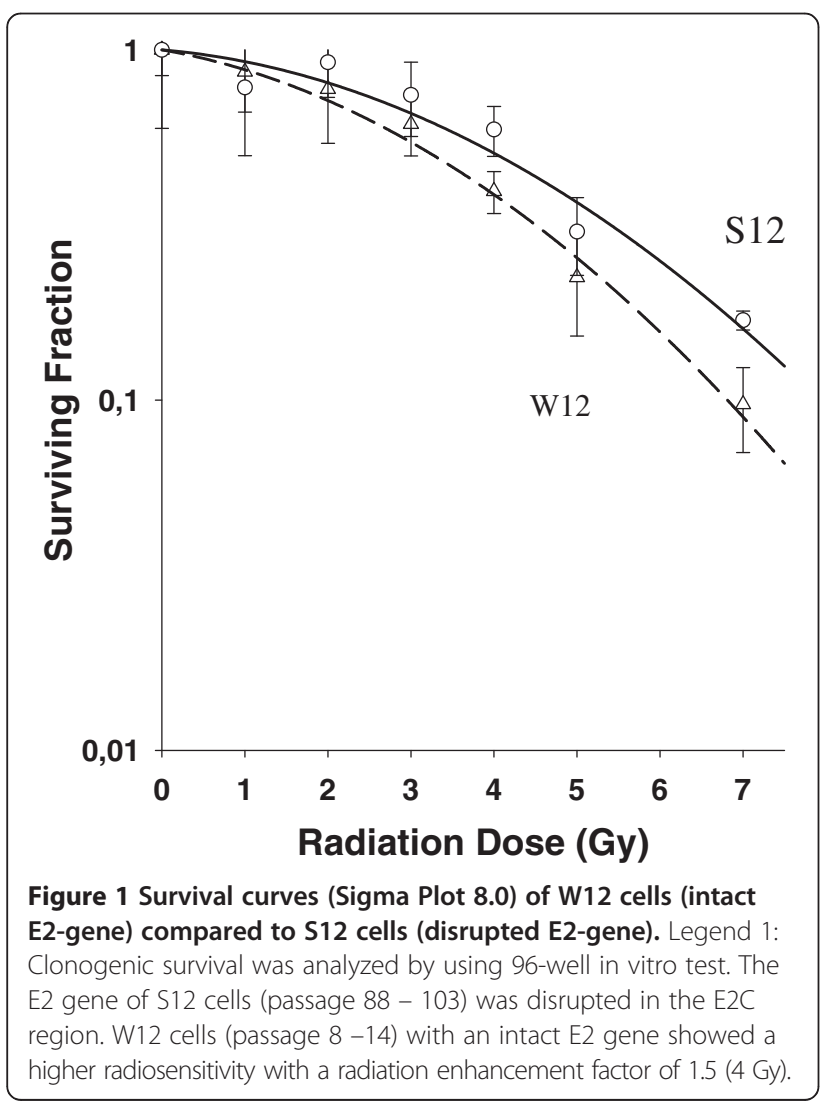

\section{E2-gene alters cell cycle regulation after radiation}

Compared to S12 cells, W12 cells (intact E2-gene) showed a G2/M-block 6 h-24 h after irradiation with 2 Gy. 48 h after 2 Gy irradiation W12 cells entered cell cycle again. After irradiation with 7 Gy G2/M-block of W12 cells lasted at least $72 \mathrm{~h}$ and resolved after 7 days. Figure 2 shows flow cytometric analysis of W12 cells $24 \mathrm{~h}$ after irradiation with 0 Gy, 2 Gy and 7 Gy. In control group $64 \%$ of cells were in G1, 9\% in S-phase and 28\% in G2/ M-phase. After irradiation with 2 Gy the amount of cells in G2/M-phase increased to $43 \%$ and after irradiation with 7 Gy to $52 \%$. In G1-phase were $49 \%$ and $40 \%$, in Sphase $8 \%$ and $7 \%$ after irradiation with 2 Gy and 7 Gy, respectively.

S12 cells (disrupted E2-gene) showed no effect like G2/M- or G1-block after irradiation with 2 Gy. S12 cells showed a G2/M-block $12 \mathrm{~h}$ to $48 \mathrm{~h}$ after irradiation with 7 Gy. $72 \mathrm{~h}$ after treatment S12 cell entered cell cycle again. Figure 3 shows flow cytomtric analysis of S12 cells $24 \mathrm{~h}$ after irradiation with $0 \mathrm{~Gy}, 2$ Gy and 7 Gy. In the control group $58 \%$ of cells were in G1, $14 \%$ in S-phase and $27 \%$ in G2/M-phase. After irradiation with 2 Gy cell distribution remained the same. After irradiation with 7 Gy $50 \%$ of cells were in G2/M-phase, $41 \%$ in G1-phase and $9 \%$ in S-phase.

S12 cells developed aneuploidy $48 \mathrm{~h}$ after 7 Gy irradiation (Figure 4). Both cell lines did not develop a G1block (Figure 2 and 3 ).

\section{E2-status changes pRb-expression after irradiation, but p53-expression is not altered}

$81 \%$ of S12 cells (disrupted E2-gene) were positive for $p R b$-expression in the control group. $24 \mathrm{~h}$ after irradiation with 2 Gy and 7 Gy $p R b$ - labeled cells dropped down to $2.3 \%$ and to $5 \%$, respectively (Figure 5 ).

W12 cells (intact E2-gene) showed 80\%, 77\% and 80\% $p R b$-labeled cells after irradiation with $0 \mathrm{~Gy}, 2 \mathrm{~Gy}$ and 7 Gy, respectively (Figure 6).

There was no significant overexpression of $p 53$ in both cell lines and no change after irradiation with 2 Gy or $7 \mathrm{~Gy}$.

\section{Discussion}

Reasons for an increased radiocurability of HPV-positive tumors are not defined yet. Disruption of the viral E2gene has been shown to be associated with poor outcome in patients with cervical cancer $[4,7,8]$. Not only in cervical cancer, but also in HPV-positive head and neck cancer E2-protein may be relevant for treatment success [15]. There is still a debate about direct influence of HPV on radiosensitivity. Because for these clinical reports and the referred interference of E2-protein with regulation of apoptosis and cell cycle control $[6,16]$ we established the W12/S12 cell system to analyze influence of E2-gene status on radiosensitivity. This cell model mimics the natural 
Figure 2 Plot of flow cytometry using PI-staining for cell cycle analysis of W12 cells (intact E2-gene). Legend 2: A = control group, $\mathbf{B}=2$ Gy $(24$ h), $\mathbf{C}=7$ Gy $(24$ h): Figure 2 shows flow cytometric analysis of W12 cells 24 h after irradiation with 0 Gy, 2 Gy and $7 \mathrm{~Gy}$. In control group 64\% of cells were in G1, 9\% in S-phase and $28 \%$ in G2/M-phase. After irradiation with $2 \mathrm{~Gy}$ the amount of cells in G2/M-phase increased to 43\% and after irradiation with 7 Gy to $52 \%$. In G1-phase were $49 \%$ and $40 \%$, in S-phase $8 \%$ and $7 \%$ after irradiation with 2 Gy and 7 Gy, respectively.

way of integration of virus leading to disruption of the E2-gene [11,12]. We could demonstrate that a disrupted E2-gene leads to radioresistance, because W12/S12 cells differ only in E2-gene status, molecular tumor background is identical. Inactivation of normal function of tumor suppressor proteins $p R b$ and $p 53$ are important steps in human cervical carcinogenesis. Mutations of tumor suppressor genes are rare in HPV-positive cervical cancer cells [17]. The loss of the E2-gene causes reduced proapoptotic signals, as well as deregulation of expression of the oncogenes E6 and E7 [18]. In response to DNA-damaging, $p 53$-levels increase by a posttranscriptional mechanism resulting in arrest via inhibition of cyclin-associated kinase activity at G1/S interface of cell cycle [19]. Loss of $p 53$ or expression of mutant $p 53$ results in failure to arrest G1 [20,21]. E6 facilitates degradation of p53 through its association with an accessory protein E6-AP, a component of ubiquitin proteolytic pathway $[17,22,23]$. In both cells types we could not detect a G1-arrest, furthermore there was no significant expression of $p 53$ in both cell types detectable. HPV E6 seems to inhibit $p 53$ effectively independently of expression of E2. Pang et al. investigated the effect of E6 and its isoforms on radiosensitivity by transfecting oral squamous cell carcinoma cells with p53 mutations. They found a radiosensitizing effect induced by E6. E6 also induced a G1-cells loss and increased apoptosis [24]. We could not demonstrate these effects in both cells types. Liu et al. found also a radiosensitizing effect of E6 [25], but others have reported opposite effect or no effect in keratinocytes and other cell types exposed to ionizing radiation [26-29].

We found a difference in cell cycle regulation regarding $\mathrm{G} 2 / \mathrm{M}$ checkpoint. Cells with an intact E2-gene showed a G2/M-block after irradiation with 2 Gy, but cells with a disrupted E2-gene needed higher doses to induce a G2/M-block. This suggests that in cells with an intact E2-gene expression of functional p53 after DNAdamage is dose dependent, because $p 53$ is required for sustaining G2/M-arrest [30]. Data showed that a given dose of radiation induces a longer G2/M-delay in radiosensitive cell lines than in matched normal or resistant cells [31]. This studies confirm our findings of S12 cells entering cell cycle after $72 \mathrm{~h}$, whereas W12 cells remained in G2/M-block more than 72 h. Furthermore 
Figure 3 Plot of flow cytometry using PI-staining for cell cycle analysis of S12 cells (disrupted E2-gene). Legend 3: $\mathbf{A}=$ control group, $\mathbf{B}=2$ Gy (24 h), $\mathbf{C}=7$ Gy (24 h): Figure 3 shows flow cytomtric analysis of $\mathrm{S} 12$ cells $24 \mathrm{~h}$ after irradiation with $0 \mathrm{~Gy}, 2 \mathrm{~Gy}$ and $7 \mathrm{~Gy}$. In the control group 58\% of cells were in G1, 14\% in S-phase and 27\% in G2/M-phase. After irradiation with 2 Gy cell distribution remained the same. After irradiation with 7 Gy $50 \%$ of cells were in G2/M-phase, 41\% in G1-phase and 9\% in S-phase.

cells with a disrupted E2-gene developed aneuploidy after irradiation but cells with an intact E2-gene did not. Liu et al. demonstrated that E6 is capable of inducing DNA replication after postmitotic checkpoint arrest and induces polyploidy independent of $p 53$ [32]. P53 plays a key role in mediating postmitotic checkpoint and because E6 targets $p 53$ for degradation, E6 induces polyploidy through inactivation of $p 53$ [33,34]. Because we could not find aneuploidy in cells with intact E2-gene our experiments indicate that E2-status influences effect of E6 on inducing aneuploidy and is triggered by irradiation. Experiments by Liu et al. showed amount of cells undergoing apoptosis was inversely correlated with polyploidy, suggesting that polyploid cells were subjected to undergo apoptotic elimination and E6 can inhibit polyploidy-associated apoptosis [32]. Radioresistence may be related to aneuploidy and inhibition of apoptosis by E6 in E2-disrupted cells.

We found down-regulation of $p R b$ in cells with disrupted E2-gene after irradiation with 2 and 7 Gy. As previously shown, E7 oncoprotein binds to hypophosphorylated $p R b$ form resulting in its degradation and inappropriate release of E2F transcription factor [10]. Decrease of $p R b$ is therefore an indirect sign of an increased expression of E7 after irradiation dependent on E2-gene

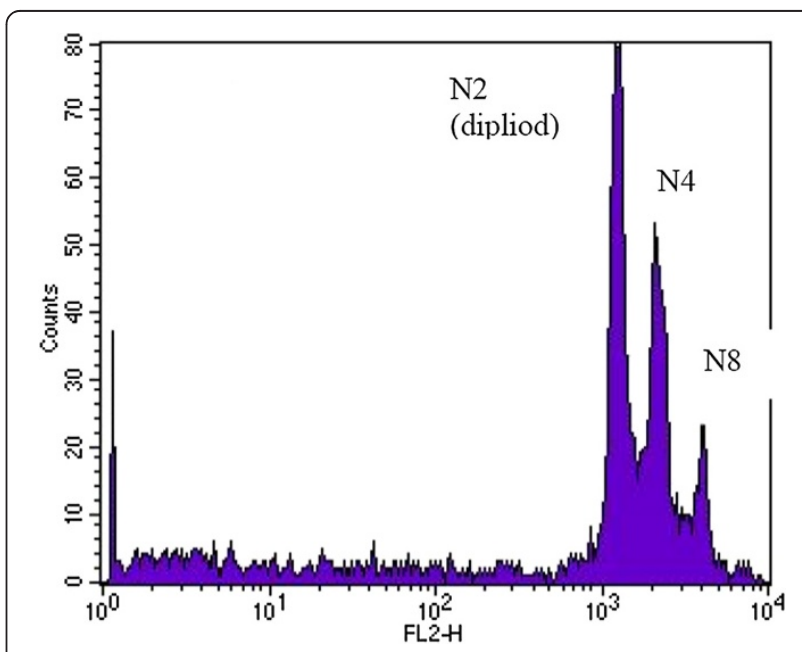

Figure 4 Plot of flow cytometry using PI-staining: S12 cells (disrupted E2-gene) developed aneuploidy $48 \mathrm{~h}$ after irradiation with $7 \mathrm{~Gy}$. 

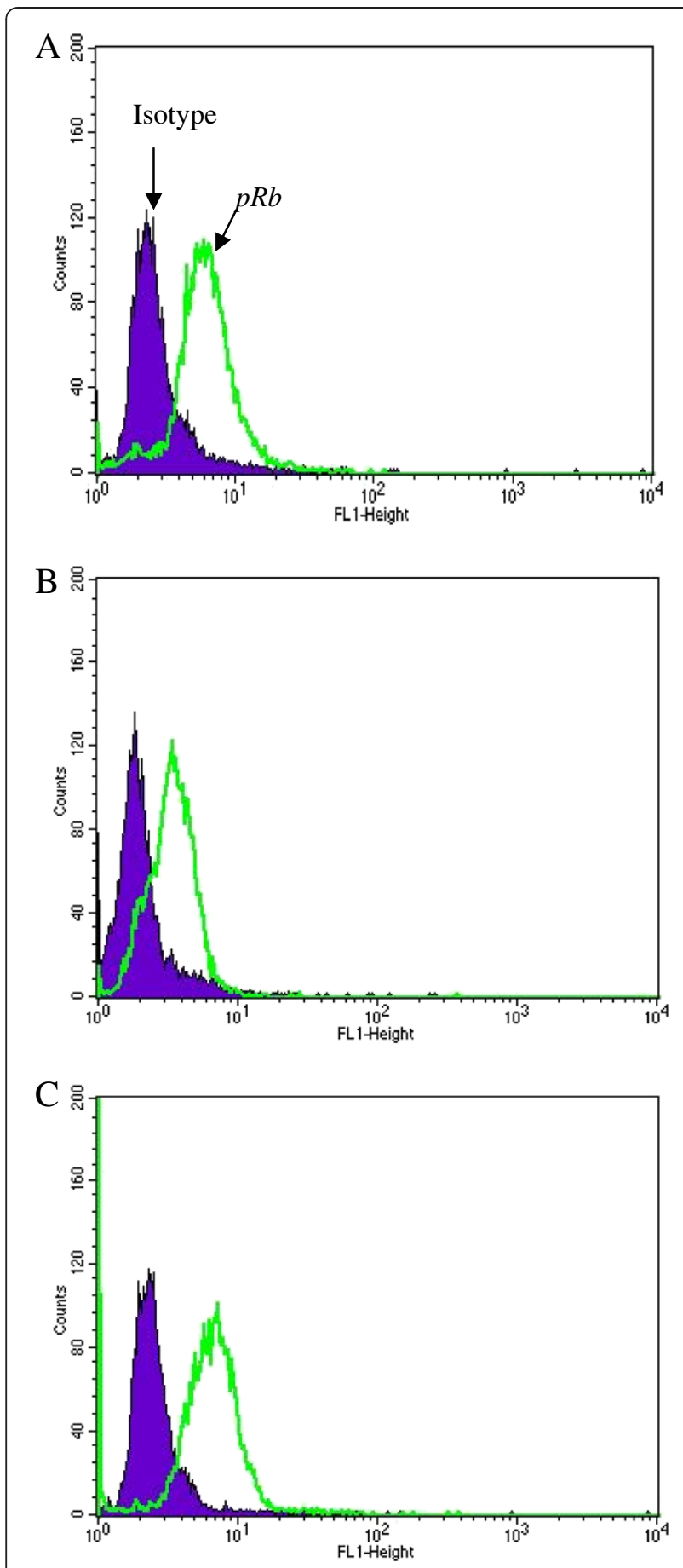

Figure 5 Plot of flow cytometry using intracellular staining: No change of $p R B$ labeling in W12 cells (intact E2-gene) after irradiation. Legend 5: $\mathbf{A}=$ control group, $\mathbf{B}=2 \mathrm{~Gy}, \mathbf{C}=7 \mathrm{~Gy}$ : In each case negative control were cells treated as described above without Rb-ak staining. Isotypic control were cells treated with isotype-matched control of irrelevant specificity from FITC Mouse IgG1 Isotype control (BD-Set\# 556538) instead of Rb-ak staining or p53-ak staining. Analyses were performed after $0 \mathrm{~h}$ and $24 \mathrm{~h}$ irradiation with 2 Gy and 7 Gy.W12 cells (intact E2-gene) showed $80 \%, 77 \%$ and $80 \%$ pRb-labeled cells after irradiation with $0 \mathrm{~Gy}$, 2 Gy and 7 Gy, respectively.
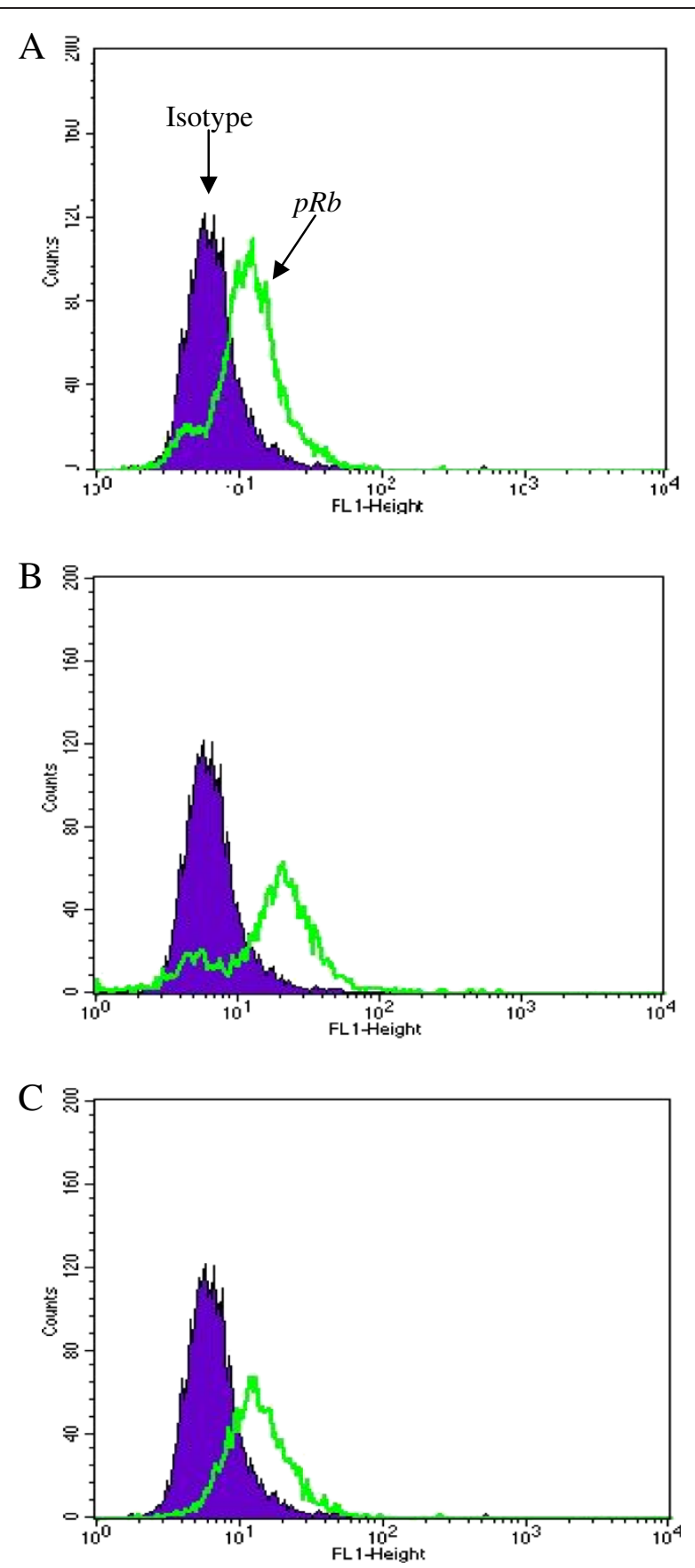

Figure 6 Plot of flow cytometry using intracellular staining: Change of $p R B$ labeling in $S 12$ cells (disrupted E2-gene) after irradiation. Legend 6: $\mathbf{A}=$ control group, $\mathbf{B}=2 \mathrm{~Gy}, \mathbf{C}=7 \mathrm{~Gy}: 81 \%$ of $\mathrm{S} 12$ cells (disrupted E2-gene) were positive for pRb-expression in the control group. $24 \mathrm{~h}$ after irradiation with $2 \mathrm{~Gy}$ and $7 \mathrm{~Gy} p R b$ labeled cells dropped down to $2.3 \%$ and to $5 \%$, respectively.

status. Santin et al. have reported that high doses of IR (12.5-100 Gy) could increase E6/E7 expression in cervical carcinoma cell lines [35]. Our experiments indicate that disrupted E2-gene in HPV positive cells lead to an overexpression of the oncogene E7 with a down-regulation of 
$\mathrm{pRb}$. Abdulkarim et al. could demonstrate that restoration of $p R b$ with cidofivor leads to increased radiosensitivity [36]. DeWeese et al. found low dose rate radiotherapy led to both G1 and G2 arrest expressing E6, but in cells expressing both E6 and E7, cells arrested only in G2. Despite this difference cell cycle arrest, no difference in clonogenic survival was seen [28]. Gammoh et al. could demonstrate that activity of E7 can be controlled through a direct interaction with E2, resulting in an inhibition of the activity of E7[37] and that E7-induced degradation of $p R b$ was rescued [38].

Our experiments confirm lack of G1-arrest independent of E2-gene status. The up-regulation of E7 reducing functional $p R b$ seems to be an essential factor for enhanced radioresistance of cells with a disrupted E2-gene.

\section{Conclusion}

Our experiment support the hypothesis that better prognosis of patients with E2-gene positive cervical cancer is determined by a better response to radiotherapy compared to HPV-positive cancers without an intact E2-gene. Not only differences in cell cycle regulation, but also regulation of expression of E7 might contribute to E2dependent radioresponse.

\section{Competing interest}

The authors declare that they have no competing interests.

\section{Authors' contributions}

$\mathrm{KL}$ conceived of the study design, performed all experiments and wrote the manuscript. SD carried out irradiation of the cells and FACS analysis. SR and KJW helped to analyze experiments. EMD contributed with regard to content and scientific context. JD conceived of the study and helped to write and finalize the manuscript. All authors read and approved the final manuscript.

\section{Author details}

'Dept. of Radiation Oncology and Radiotherapy, University of Heidelberg, Im Neuenheimer Feld 400, Heidelberg 69120, Germany. ${ }^{2}$ Division of Tumorvirus Characterisation, Deutsches Krebsforschungszentrum, Im Neuenheimer Feld 242, Heidelberg 69120, Germany.

Received: 14 September 2012 Accepted: 26 October 2012 Published: 7 November 2012

\section{References}

1. Zur Hausen H: Immortalization of human cells and their malignant conversion by high risk human papillomavirus genotypes. Semin Cancer Biol 1999, 9:405-411.

2. Spandidos DA, Dokianakis DN, Kallergi G, Aggelakis E: Molecular basis of gynecological cancer. Ann N Y Acad Sci 2000, 900:56-64.

3. Scheffner M, Romanczuk H, Munger K, Huibregtse JM, Mietz JA, Howley PM: Functions of human papillomavirus proteins. Curr Top Microbiol Immunol 1994, 186:83-99.

4. Kalantari M, Karlsen F, Kristensen G, Holm R, Hagmar B, Johansson B: Disruption of the E1 and E2 reading frames of HPV 16 in cervical carcinoma is associated with poor prognosis. Int J Gynecol Pathol 1998, 17:146-153.

5. Vernon SD, Unger ER, Reeves WC: Human papillomaviruses and anogenital cancer [letter; comment]. N Engl J Med 1998, 338:921-922.

6. Desaintes C, Goyat S, Garbay S, Yaniv M, Thierry F: Papillomavirus E2 induces p53-independent apoptosis in HeLa cells. Oncogene 1999 18:4538-4545.
7. Lindel $\mathrm{K}$, de Villiers EM, Burri P, Studer U, Altermatt HJ, Greiner RH, Gruber G: Impact of viral E2-gene status on outcome after radiotherapy for patients with human papillomavirus 16-positive cancer of the uterine cervix. Int J Radiat Oncol Biol Phys 2006, 65:760-765. Epub 2006 May 6

8. Vernon SD, Unger ER, Miller DL, Lee DR, Reeves WC: Association of human papillomavirus type 16 integration in the E2 gene with poor disease-free survival from cervical cancer. Int J Cancer 1997, 74:50-56.

9. Thomas M, Pim D, Banks L: The role of the E6-p53 interaction in the molecular pathogenesis of HPV. Oncogene 1999, 18:7690-7700.

10. Berezutskaya E, Yu B, Morozov A, Raychaudhuri P, Bagchi S: Differential regulation of the pocket domains of the retinoblastoma family proteins by the HPV16 E7 oncoprotein. Cell Growth Differ 1997, 8:1277-1286.

11. Stanley MA, Browne HM, Appleby M, Minson AC: Properties of a nontumorigenic human cervical keratinocyte cell line. Int J Cancer 1989, 43:672-676.

12. Bechtold V, Beard P, Raj K: Human papillomavirus type $16 \mathrm{E} 2$ protein has no effect on transcription from episomal viral DNA. J Virol 2003, 77:2021-2028

13. Kersch RL, Thilly WG: Internal standards for survival: increasing the accuracy for human cell mutation assays. Mutat Res 1987, 182:83-97.

14. Schafer J, Bachtler J, Engling A, Little JB, Weber KJ, Wenz F: Suppression of apoptosis and clonogenic survival in irradiated human lymphoblasts with different TP53 status. Radiat Res 2002, 158:699-706.

15. Lindel K, Beer KT, Laissue J, Greiner RH, Aebersold DM: Human papillomavirus positive squamous cell carcinoma of the oropharynx: a radiosensitive subgroup of head and neck carcinoma. Cancer 2001, 92:805-813.

16. Desaintes C, Demeret C, Goyat S, Yaniv M, Thierry F: Expression of the papillomavirus E2 protein in HeLa cells leads to apoptosis. EMBO J 1997, 16:504-514.

17. Scheffner M, Munger K, Byrne JC, Howley PM: The state of the $p 53$ and retinoblastoma genes in human cervical carcinoma cell lines. Proc Natl Acad Sci USA 1991, 88:5523-5527.

18. Alazawi W, Pett M, Strauss S, Moseley R, Gray J, Stanley M, Coleman N: Genomic imbalances in 70 snap-frozen cervical squamous intraepithelial lesions: associations with lesion grade, state of the HPV16 E2 gene and clinical outcome. Br J Cancer 2004, 91:2063-2070.

19. Chen $X$, Ko L, Jayaraman L, Prives C: p53 levels, functional domains, and DNA damage determine the extent of the apoptotic response of tumor cells. Genes Dev 1996, 10:2438-2451.

20. Livingstone LR, White A, Sprouse J, Livanos E, Jacks T, TIsty TD: Altered cell cycle arrest and gene amplification potential accompany loss of wildtype p53. Cell 1992, 70:923-935.

21. Yin Y, Tainsky MA, Bischoff FZ, Strong LC, Wahl GM: Wild-type p53 restores cell cycle control and inhibits gene amplification in cells with mutant p53 alleles. Cell 1992, 70:937-948.

22. Scheffner M, Huibregtse JM, Vierstra RD, Howley PM: The HPV-16 E6 and E6-AP complex functions as a ubiquitin-protein ligase in the ubiquitination of p53. Cell 1993, 75:495-505.

23. Werness BA, Levine AJ, Howley PM: Association of human papillomavirus types 16 and 18 E6 proteins with p53. Science 1990, 248:76-79.

24. Pang E, Delic NC, Hong A, Zhang M, Rose BR, Lyons JG: Radiosensitization of oropharyngeal squamous cell carcinoma cells by human papillomavirus 16 oncoprotein E6 *. Int, 79:860-865. Epub 2010 Nov 23.

25. Liu ZG, Zhao LN, Liu YW, Li TT, Fan DM, Chen Jj: Activation of Cdc2 contributes to apoptosis in HPV E6 expressing human keratinocytes in response to therapeutic agents. J Mol Biol 2007, 374:334-345. Epub 2007 Sep 18.

26. Hampson L, El Hady ES, Moore JV, Kitchener H, Hampson IN: The HPV16 E6 and $\mathrm{E7}$ proteins and the radiation resistance of cervical carcinoma. FASEB J 2001, 15:1445-1447.

27. Huang RP, Fan Y, Peng A, Zeng ZL, Reed JC, Adamson ED, Boynton AL: Suppression of human fibrosarcoma cell growth by transcription factor, Egr-1, involves down-regulation of Bcl-2. Int J Cancer 1998, 77:880-886

28. DeWeese TL, Walsh JC, Dillehay LE, Kessis TD, Hedrick L, Cho KR, Nelson WG Human papillomavirus E6 and E7 oncoproteins alter cell cycle progression but not radiosensitivity of carcinoma cells treated with low-dose-rate radiation. Int J Radiat Oncol Biol Phys 1997, 37:145-154

29. Shai A, Brake T, Somoza C, Lambert PF: The human papillomavirus E6 oncogene dysregulates the cell cycle and contributes to cervical 
carcinogenesis through two independent activities. Cancer Res 2007, 67:1626-1635.

30. Bunz F, Dutriaux A, Lengauer C, Waldman T, Zhou S, Brown JP, Sedivy JM, Kinzler KW, Vogelstein B: Requirement for p53 and p21 to sustain G2 arrest after DNA damage. Science 1998, 282:1497-1501.

31. Nagasawa H, Keng P, Harley R, Dahlberg W, Little JB: Relationship between gamma-ray-induced G2/M delay and cellular radiosensitivity. Int J Radiat Biol 1994, 66:373-379.

32. Liu Y, Heilman SA, Illanes D, Sluder G, Chen JJ: p53-independent abrogation of a postmitotic checkpoint contributes to human papillomavirus E6-induced polyploidy. Cancer Res 2007, 67:2603-2610.

33. Thomas M, Banks L: Inhibition of Bak-induced apoptosis by HPV-18 E6. Oncogene 1998, 17:2943-2954.

34. Thompson DA, Belinsky G, Chang TH, Jones DL, Schlegel R, Munger K: The human papillomavirus-16 E6 oncoprotein decreases the vigilance of mitotic checkpoints. Oncogene 1997, 15:3025-3035.

35. Santin AD, Hermonat PL, Ravaggi A, Chiriva-Internati M, Pecorelli S, Parham GP: Radiation-enhanced expression of E6/E7 transforming oncogenes of human papillomavirus-16 in human cervical carcinoma. Cancer 1998, 83:2346-2352

36. Abdulkarim B, Sabri S, Deutsch E, Chagraoui H, Maggiorella L, Thierry J, Eschwege F, Vainchenker W, Chouaib S, Bourhis J: Antiviral agent Cidofovir restores $\mathrm{p} 53$ function and enhances the radiosensitivity in HPVassociated cancers. Oncogene 2002, 21:2334-2346.

37. Gammoh N, Grm HS, Massimi P, Banks L: Regulation of human papillomavirus type $16 \mathrm{E} 7$ activity through direct protein interaction with the E2 transcriptional activator. J Virol 2006, 80:1787-1797.

38. Gammoh N, Isaacson E, Tomaic V, Jackson DJ, Doorbar J, Banks L: Inhibition of HPV-16 E7 oncogenic activity by HPV-16 E2. Oncogene 2009, 28:2299-2304. Epub 2009 May 4.

doi:10.1186/1748-717X-7-187

Cite this article as: Lindel et al:: The transcriptional regulator gene E2 of the Human Papillomavirus (HPV) 16 influences the radiosensitivity of cervical keratinocytes. Radiation Oncology 2012 7:187.

\section{Submit your next manuscript to BioMed Central and take full advantage of:}

- Convenient online submission

- Thorough peer review

- No space constraints or color figure charges

- Immediate publication on acceptance

- Inclusion in PubMed, CAS, Scopus and Google Scholar

- Research which is freely available for redistribution 